\title{
POTENTIAL RISKS AND SOME OF SOLUTIONS FOR IMPLEMENTING LA 21 IN LITHUANIA
}

\author{
Audrone Alijosiute \\ Vaiva Ramansuskiene \\ ECAT, Lithuania
}

Lithuania together with Latvia and Estonia are the countries considered to be a common Baltic Sea Region due to similar economical and political situation formed in the course of history during the Soviet occupation. All three East Baltic States are currently undergoing remarkable political, economical, socio- cultural changes, which started after the Independence has been regained.

Although Local Agenda 21 has already been developed for a large number of cities in the Baltic Sea Region, Lithuania hasn't Agenda 21 strategy at the national level and its experience with Agenda's 21 implementation is very limited. In May, 1999, Zvejone (Environmental Club, part of Lithuanian Green Movement) has started project "Agenda's 21 activities in Lithuania" which lately concluded that despite various documents, resolutions, and action plans for implementation of Agenda 21 in Lithuania, almost nothing concrete is done at the national level and there is no national policy on Agenda 21 in Lithuania.

Only two cities in Lithuania, Kaunas and Klaipeda, are participating in international cooperation projects and preparing together with international partners Local Agendas 21 for their cities. In general the LA21 knowledge is at quite low level. One of the reasons of that is that the authorities and citizens did not receive sufficient information about the Rio documents since the these documents were not in time translated and published. There is lack of training officials who are working to implement sustainable development strategies at local level. Ministry of Environmental Protection does not provide with guidelines for local level.

\section{What is Local Agenda 21?}

Local Agenda 21 is a tool and a method for local authorities to achieve sustainable development. It is the process of drawing up and implementing local sustainable development plans, with the local authority working in partnership with all sectors in the local community to achieve this.

There are hundreds of ways of doing Local Agenda 21. In each local authority the process, plans and strategies are different, since they evolve from the local conditions. Thus Local Agenda 21 
can be defined to be any participatory, local effort to establish a comprehensive action strategy for sustainable development in that area.

It this presentation I'll concentrate particularly on one case study: "Kaunas Local Agenda 21". Project was financed by PHARE, Kaunas, Lithuania and Tampere, Finland. Project started in summer 1998 and ended in 1999, August. The goal of the project was to elaborate the Environmental Policy and it's implementation plan together with all interest groups also to design and start to implement Environmental Management System in Kaunas City Municipality. It has to be mentioned that the project had very ambitious goals and too tied timetable for the implementation. Despite all that it is considered to be the successful one.

Kaunas is the second largest city in Lithuania. The present population is about 415.000 .

There were about $25 \%$ of industry of the country situated in Kaunas in soviet time. Thought at present the industry is mainly active in the fields of light industry, the past activities caused enormous environmental problems such as air pollution, soil contamination, water pollution, and landscape degradation. A light industry prevailing in Kaunas City at present: are: food, textile, cloths manufacturing, paper production. The unemployment rate is $8 \%$. There are 7 universities in the City.

One important aspect is the fact that Kaunas has historically been a pioneering city in Lithuania in terms of environmental management at the municipal level. Kaunas was one of the first cities in Lithuania where environmental protection unit has been established within the municipal structure. Since 1990, Kaunas has had the first 'green' vice-mayor. This could be traced as a beginning of environmental management system: not only tackling environmental issues at the level of Kaunas Municipality, but integrating such activities in the general structure of local authority with an explicit commitment expressed by its' top management.

During the last decade or so, efforts in the field of environmental protection in the city of Kaunas, led by the Environmental Protection Division, have been often undertaken with explicit support from top-management and in close interaction with other municipal departments and external stakeholders. Development of Kaunas' municipal wastewater treatment plant is one of the most illustrative examples of integrated multi-stakeholder approach to environmental management at the municipal level. Development of a municipal waste management system, including household waste sorting, is another example of close interaction between various municipal units and external stakeholders in dealing with priority environmental issues in the city of Kaunas.

ECAT-Lithuania, situated in Kaunas, is a support unit for Lithuanian cities on environmental issues. There are 15 employees in the ECAT at the moment. It played the key role in practical management of the project Local Agenda 21 - Kaunas. ECAT - Lithuania has been active in LA21 field since 1997. It has organised a lot of conferences, seminars, trainings for municipalities, published a lot of the material on LA2 1 topic. 


\section{The case :}

\section{Local Agenda 21 - Kaunas}

The aim of the project is development of Environmental Policy (strategy and action plan) for Kaunas-city.

Assessment of current situation, analysis of partners' experience and training of municipal policy-makers and officials on sustainability issues will provide a basis for its achievement. Raising public awareness and participation in decision-making is an integral part of all project activities.

\section{Objectives of the project:}

- assessment of the correspondence of current municipal environmental policy with the national and EU legislation and international agreements;

- evaluation of the environmental management system in Kaunas municipality in accordance with criteria of sustainable development;

- investigation of social identity to promote community development and improve public relations;

- establishment of partnerships for the development of Agenda 21 for the Baltic Sea Region;

- preparation of the training program on sustainability issues and training of policy- and decisionmakers as well as of municipal officials;

- analysis of partners' experience and adaptation of Local Agenda 21 Planning Guide;

- development of Environmental Policy (strategy and action plan) for Kaunas-city, particularly defining the role and functions of the Department of Environmental Protection as a coordinator of it's implementation;

Five subgroups were founded out in order to carry on the implementation of the project. At the end of the project each group produced final report which evaluated the progress of project activities also gave recommendations for future.

\section{Evaluation}

Project Local Agenda 21 - Kaunas is the first LA21 project in Lithuania. It has to be stressed that particularly local experts were the main implementers of the project ( 12 Lithuanian experts form 16 total)

The main goal of the project was successfully achieved: Environmental Policy and strategy for its implementation were elaborated in co-operation with various stakeholders and also in correspondence with Baltic 21, and it is very important for the sustainable development process of the city. It has to be stated that the completion of the project does not mean the completion of the process of Local Agenda 21. The PHARE grant provided a good basis to start LA21 process, because lack of finances is usually listed among the main obstacles while implementing LA21.

During the project period four issues of supplements to "Kauno Diena " Lithuanian daily newspaper were published. Six mini reports on project progress produced (also available on 
internet ) and disseminated. There were a lot of participants in the seminars from other municipalities what made the results, lessons available for large group of interested people.

Fruitful co-operation of various experts / consultants and the municipality staff during the project took place, and new partnerships were established. Diversity of view - points and scientific background in combination with the experience of municipal work, certainly, was the advantage of the project. Project coordinators pointed out the exchange of the experience between municipality and universities as the greatest achievement of the project. The fifteen workshops on sustainability issues contributed to capacity of municipal civil servants when dealing with environmental issues at local level. Nearly 300 participants attended the workshops.

A discussion with partners from Finland was an important source of inspiration giving new ideas and practical suggestions for the implementation. One of the requirements of good co-operation is that the partners know each other. It is necessary to know all the people involved in the project from the beginning of the project. A starting meeting with all the participants is needed at the very beginning of the project and it should take place in the home cities of the partners. In this way people involved in the project would get more familiar with their partner's daily work and the organisation.

During the work, team of external experts did not encounter any serious problems. City municipality staff had been co-operative and responsive. Requested documentation had been provided in time and at full extent. Co-operation from top management, including city Mayor, was very good, especially at the initial stage of the work. The high involvement of City Administrator Mr. R. Noreika during the second stage of the project had shown that there are changes in traditional way of thinking and perception of environmental issues in Kaunas Municipality.

Evaluating weaknesses of the project main problem is the lack of foreign language skills. The main people involved in the project both from Lithuania and Finland know English but it is not their mother tongue. Some people participating in the project do not know English. Management of this type of project is the very first experience in Lithuanian Municipalities.

The one who is familiar with LA21 definition would criticise the project from the point of view of weak public participation. Thought knowing the contemporary situation (social, economical and political) in Lithuanian municipalities it has to be stated that project was exactly right way to start. Why:

- general level of public participation is very low

- there is no proper contacts with NGO's

- municipal staff was not well enough educated in order to go outside with LA21 


\section{EMS and Local Agenda 21}

Development of an integrated environmental management system in the Kaunas city Municipality is regarded as a tool or mechanism which helps integrating environmental considerations into daily practices and decisions taken at various levels of municipal management structure. Therefore, it is important to see EMS in a broader context and integrate it with overall efforts of social, environmental and economic development in Kaunas community which have been encompassed under the Local Agenda 21.

To ensure successful implementation of the environmental policy and action plan, it is necessary to reshape the internal structure of the municipal Environmental Protection Division (EPD) and its' external interactive linkages with other relevant units of Kaunas' Municipality. Both types of structural changes have to be coherent with the need to meet requirements and address priority issues of municipal environmental policy and ensure institutional capacity to implement environmental action plan.

The main direction in linking EMS with LA21 is through more close networking between actors and municipal units involved in EMS and those that are important for social-economic development of Kaunas city. First of all, those are the municipal divisions dealing with issues of finance, business development, social security, and others. Such networking would be coordinated by a new public officer who would be institutionalised in the office of Municipality's Administrator.

This kind of perspective network linking EMS and LA21 in the city of Kaunas is illustrated in the picture as follows. 
Linking Local Agenda 21 network and environmental management system in the structure of

Kaunas Municipality

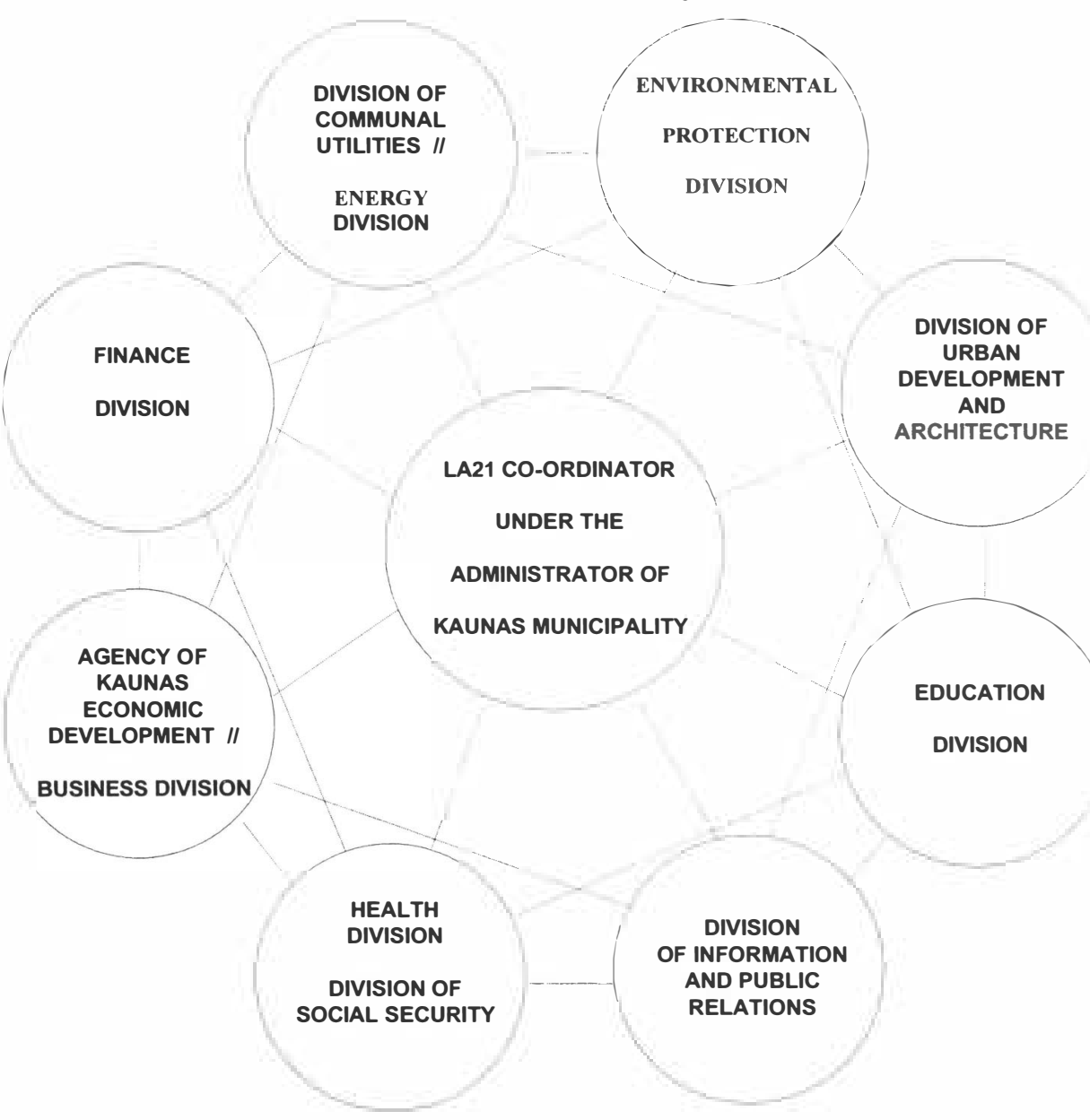


The overall experience of the project is of great importance because not only Kaunas City can use all the materials and reports produced during the project but also it can be used by other municipalities when starting Local Agenda 21 processes.

The main lessons learned:

- project has to have achievable, realistic, not too ambitious goals

- implementation and even the development of environmental management system requires more time then one year

- communication with public have to be performed in more interactive way

- exchange of Know How with partners can be very efficient if proper communication is established in the beginning

- commitment of top management is very important 